\title{
GCU
}

Glasgow Caledonian

University

University for the Common Good

\section{Physical function and health-related quality of life in older adults with or at risk of mobility disability post-discharge: 8-month follow-up of a randomised controlled trial}

Sunde, Sylvia; Hesseberg, Karin; Skelton, Dawn A.; Ranhoff, Anette H.; Pripp, Are H.;

Aarønæs , Marit; Brovold, Therese

Published in:

Journal of Aging and Physical Activity

DOI:

10.1123/japa.2020-0522

Publication date:

2022

Document Version

Author accepted manuscript

Link to publication in ResearchOnline

Citation for published version (Harvard):

Sunde, S, Hesseberg, K, Skelton, DA, Ranhoff, AH, Pripp, AH, Aarønæs, M \& Brovold, T 2022, 'Physical function and health-related quality of life in older adults with or at risk of mobility disability post-discharge: 8month follow-up of a randomised controlled trial', Journal of Aging and Physical Activity, vol. 30, no. 3, pp. 404410. https://doi.org/10.1123/japa.2020-0522

\section{General rights}

Copyright and moral rights for the publications made accessible in the public portal are retained by the authors and/or other copyright owners and it is a condition of accessing publications that users recognise and abide by the legal requirements associated with these rights.

Take down policy

If you believe that this document breaches copyright please view our takedown policy at https://edshare.gcu.ac.uk/id/eprint/5179 for details

of how to contact us. 


\section{Journal of Aging and Physical Activity}

\section{Physical Function and Health-Related Quality of Life in older adults with or at risk of mobility disability post-discharge: 8-month follow-up of a randomized controlled trial}

\begin{tabular}{|c|c|}
\hline Journal: & Journal of Aging and Physical Activity \\
\hline Manuscript ID & JAPA.2020-0522.R1 \\
\hline Manuscript Type: & Original Research \\
\hline Focus Area: & $\begin{array}{l}\text { rehabilitation < clinical populations, disability < clinical populations, } \\
\text { cardiovascular < exercise physiology, class / group-based (including role } \\
\text { of the instructor) < interventions, physical fitness, quality of life / } \\
\text { wellbeing < psychosocial perspectives, randomised controlled trials < } \\
\text { quantitative studies, aerobic < type of exercise, balance training < type } \\
\text { of exercise, resistance < type of exercise }\end{array}$ \\
\hline Statistical Methods: & linear mixed models for repeated measurements \\
\hline Free-Form Keywords: & $\begin{array}{l}\text { hospitalization, physical function, health-related quality of life, exercise } \\
\text { program }\end{array}$ \\
\hline
\end{tabular}

\section{SCHOLARONE Manuscripts}


2 Physical Function and Health-Related Quality of Life in older adults with or at risk of 3 mobility disability post-discharge: 8-month follow-up of a randomized controlled trial 4 5

6

7

8

9

10

11 


\section{UNSTRUCTURED ABSTRACT:}

3 The objective of this study was to evaluate physical function and health-related quality of life

4 (HRQOL) four months after cessation of a 4-month exercise intervention in 89 older adults

5 after discharge from hospital. Linear mixed regression models were used to evaluate between

6 group differences. Data were analyzed according to the intention-to treat principle. There was

7 no statistically significant between group difference in the Short Physical Performance

8 Battery (mean difference 0.5 -point, $95 \%$ confidence interval $(\mathrm{CI})-0.6$ to $1.5, \mathrm{p}=0.378$ ).

9 There was a statistically significant difference in favor of the intervention group in functional capacity (the six-minute walk test) (mean difference 32.9 meters, 95\% CI 1.5 to $64.3, \mathrm{p}=$ 0.040) and physical HRQOL (physical component summary of SF-36) (mean difference 5.9 points, $95 \%$ CI 2.0 to $9.7, \mathrm{p}=0.003$ ). Interventions aiming to maintain or increase physical function and HRQOL should be encouraged in this population.

Key words: hospitalization, exercise interventions, healthy ageing 


\section{INTRODUCTION}

3 Healthy ageing has received increased attention in international public health policy and is

4 described as a process aiming to develop and maintain the functional ability that enables well-

5 being in older age (WHO, 2015, 2017). Physical function is a broad, multidimensional concept that reflects motor function and control, physical fitness, and habitual physical activity defined as 'the capacity of an individual to carry out the physical activities of daily living (Garber et al., 2011). Studies have shown that physical function is an independent predictor of functional independence, disability, morbidity, and mortality (Brown et al., 2020; Fried et al., 1999; Garber et al., 2010; Pavasini et al., 2016). Furthermore, health related quality of life (HRQOL) is considered a key indicator of older people's health status (Machón et al., 2017). HRQOL can be defined as 'a multidomain concept that represents the patient's overall perception of the impact of an illness and its treatment. An HRQL measure captures, at a minimum, physical, psychological (including emotional and cognitive), and social functioning' (Health et al., 2006). Thus, both physical function and HRQOL are important measures related to healthy ageing.

For people $\geq 65$ years hospitalization is associated with decline in physical function and it might also affect HRQOL (Brown et al., 2016; Helvik et al., 2013). Those who present with mobility disabilities while being an inpatient are especially at risk of functional decline (Buurman et al., 2011). The focus on the deleterious consequences of low physical activity during and after a hospital stay has received increasing attention in the last decades (Brown et al., 2009; Gill et al., 2004). Different exercise interventions have been performed to counteract these consequences (Brovold et al., 2013; Bruun et al., 2018), but the evidence for effect of exercise programs in this population is not robust (Loyd et al., 2018; McKelvie et al., 2018; Verweij et al., 2019). Furthermore, the longer-term effects on physical function and HRQOL of such exercise programs are not established. 
A recent umbrella review of systematic reviews recommends multicomponent exercise interventions to improve muscular strength, gait speed, balance and physical performance in pre-frail and frail older adults (Jadczak et al., 2018). Exercise and physical activity are also associated with significant improvements in overall psychological well-being in older adults (American College of Sports et al., 2009). However, many studies have shown that the physiological adaptions associated with an exercise intervention are quickly lost upon cessation of training (American College of Sports et al., 2009). This phenomenon known as detraining has also been reported to affect quality of life in older adults (Tomas-Carus et al., 2007), although the evidence is conflicting (Esain et al., 2019).

The immediate effects of a group-based multicomponent high intensity exercise program on physical function and HRQOL in older adults with or at risk of mobility disability after discharge from hospital have been recently explored (Sunde et al., 2020). The authors found a statistically significant and clinically relevant between group difference in functional capacity (the six-minute walk test) and physical HRQOL (physical component summary of the SF-36) in favor of the intervention group after four months of training. To evaluate how long the effects of an exercise intervention persist after the intervention has ended is important for multiple reasons, especially when allocating resources and planning of health care services. The aim of the current study was to evaluate physical function and HRQOL in a group of older adults with or at risk of mobility disability after discharge from hospital four months after the cessation of the intervention in a randomized controlled trial.

\section{METHODS}

The present study reports on follow-up data four months after completion of the intervention in a parallel group randomized controlled trial. Reporting is according to the CONSORT 2010 


\section{Settings and participants}

\section{Randomization}

statement (Schulz et al., 2010). The study was approved by the Regional Committee for Medical Research Ethics (Ref. 2015/2432). The study was registered in Clinical Trials (NCT02905383) on September 19, 2016, before the recruitment of the first participant.

The study was conducted at a general hospital. Participants were recruited while inpatient, based on patient registration lists from four medical wards from September 2016 to May 2019. The recruitment ended before the required sample size was reached because of slow recruitment rate and limited resources. The last follow-up occurred in January 2020.

Eligibility criteria were: Age $\geq 65$ years, community-dwelling pre-admission, be at risk of mobility disability defined as a Short Physical Performance Battery (SPPB) of $<10$ while inpatient (Guralnik et al., 2000; Guralnik et al., 1994), able to walk independently with or without walking aid, no moderate or severe cognitive disorder (Score on Mini Mental State Examination $\geq 20$ ) (Folstein et al., 1975), an expected lifespan of at least eight months and understand Norwegian language. People who exercised regularly more than twice a week at a fitness center or in a structured exercise program before admission were excluded. Further, participants who a doctor in the study group found ineligible to the intervention based on the standards from the American Heart Association were excluded (Fletcher et al., 2013). All participants provided written informed consent prior to baseline testing.

Allocation to an intervention group or a control group was done after baseline testing, based on a computer-generated permuted block randomization scheme. Each block contained 
between four to ten subjects. Two of the authors with no information about the participants administered the scheme, and sealed envelopes were used.

\section{Intervention and control group}

The intervention was a group-based multicomponent high intensity exercise program instructed by a physical therapist one hour twice a week for four months. In short, each exercise session consisted of a warm-up period and three bouts of high intensity endurance training interspersed by two strength exercises for the lower limbs, six balance exercises and flexibility exercises. Both the intervention group and the control group were instructed in home balance and strength exercises after completing all the outcome measures at baseline, lasting approximately 15 minutes, and they were given a printout of the exercise program. All participants were encouraged to perform the exercises at least three times each week during the study period ( 8 months). The home balance and strength exercises were also included in the high intensity multicomponent exercise intervention. Therefore, during the course of the intervention the participants in the intervention group were encouraged to perform the exercises at least once a week at home if they had attended the intervention session twice that week. This home exercise program was developed by physical therapists from the Norwegian University of Science and Technology (NTNU) and Trondheim Municipality in 2016, founded by the Norwegian Directorate of Health (NDH, 2016). In addition, all participants were encouraged to follow the World Health Organization recommendations on physical activity for people $65+$ over the entire eight months the study was ongoing (WHO, 2010). Apart from this, the participants in the control group received treatment as usual. Regardless of group allocation, there was no planned contact between the participants and the study team during the 4-months follow-up after the end of the intervention. 


\section{Outcome measures}

3 Trained physical therapists, blinded to group allocation, assessed the outcome measures at

4 baseline, after completion of the intervention (4 months) and at 8-month follow-up.

5 Background information about age, sex, education, living alone or with someone, discharge

6 diagnosis, number of comorbidities at the time of discharge, and length of hospital stay were

7 collected from the participants hospital records or by asking the participants at baseline

8 testing.

\section{Primary outcome}

Primary outcome was physical function, measured by the SPPB, at 4 months (Guralnik et al., 1994). The battery evaluates the person's ability to stand in side by side, semi tandem and tandem position for ten seconds, preferred 4-meter walking speed and time to sit and stand five times.

\section{Secondary outcomes}

Physical function at 8 months was measured by the SPPB (Guralnik et al., 1994).

Performance-based balance was measured using the Berg Balance Scale (BBS) (Halsaa et al., 2007). Muscle strength (grip strength) was measured by Jamar dynamometer (Bohannon, 2017). Functional capacity was assessed using the six-minute walk test (Crapo et al., 2002). Body Mass Index (BMI) was measured by a Tanita BC-418 Body Composition 131 Analyzer or a regular body scale, using the formula $\left(\mathrm{kg} / \mathrm{m}^{2}\right)$. Finally, HRQOL was measured by the Medical Outcome Study 36 Item Short-Form Health Survey, version 2 (SF-36) (Ware \& Sherbourne, 1992). The 36 items in SF-36 are grouped into eight health status scales, and a physical and a mental component score are calculated. If possible, the participant filled out 


\section{$7 \quad$ Sample size}

the questionnaires received by mail (SF-36) at home before testing. Help to complete the questionnaires (if needed) was provided by the physical therapist by interview. We also asked the participants to fill in activity diaries. However, after feedback from the first 20 participants we decided to omit activity diaries as they found them burdensome.

The sample size was estimated based on the primary outcome, physical function (SPPB) immediately after the end of the intervention in a randomized controlled trial, four months after baseline testing. A medium meaningful difference between the groups in change of SPPB from baseline to intervention end (at four-month follow-up) was defined to 0.75 points with an expected standard deviation (SD) of 1.48 points (Perera et al., 2006). To obtain $80 \%$ statistical power with a 5\% significance level, 126 participants, 63 in each group, was needed. We aimed to include at least 150 participants, to compensate for potential dropouts.

\section{Statistical methodology}

All analyses were conducted using SPSS 25.0 (SPSS Corporation, Chicago, IL, USA). The data were analyzed following the intention-to-treat principle (ITT). Between group differences at four-months follow-up after the intervention (8 months) were assessed using linear mixed models for repeated measurements with a subject-specific random intercept. Type of treatment (intervention or control), baseline values, time and the interaction between time and group being modelled as fixed effects. P-values $<0.05$ were considered statistically significant and all tests were two sided. 


\section{RESULTS}

\section{$3 \quad$ Participants}

4 In total, 89 participants aged 65 to 89 years were recruited to the intervention study. The mean 5 (SD) age of the participants was 78.3 (5.5) years, with a median of 78 years. One participant withdrew and asked for his data to be deleted, hence we report on 88 participants at baseline. Baseline testing was conducted a median of 49 (interquartile range (IQR 26-116)) days after discharge. Characteristics of the sample are presented in Table 1. Thirty-one participants were lost to follow-up at the second follow up. These 31 participants scored significantly lower on SPPB at baseline than those who attended testing at eight months follow up (mean difference (95\% confidence interval (CI)) $1.7(0.7-2.6))$. Further detail on the flow of the participants is shown in Figure 1. Eight of the 31 participants $(25.8 \%)$ in the intervention group that performed SPPB at eight-month follow-up achieved the highest possible score of 12 points. The corresponding numbers for the control group were 5 of 26 participants (19.2\%). Immediately after the end of the intervention (at four-month follow-up) 10 out of 29 (22.7\%) in the intervention group and 5 out of $30(11.4 \%)$ in the control group reached the full score of SPPB.

\section{Repeated measurements}

Table 1 presents descriptive statistics of the intervention group and the control group at baseline, 4 months and 8 months. Table 2 shows the results at 8 months follow-up. There was no statistically significant between group difference in physical function (SPPB) (mean difference 0.5 -point, $95 \% \mathrm{CI}-0.6$ to $1.5, \mathrm{p}=0.378$ ). There was a statistically significant difference in favor of the intervention group in the six-minute walk test (mean difference 32.9 meters, $95 \%$ CI 1.5 to $64.3, p=0.040$ ). Further, there were no statistically significant between group differences on other secondary outcomes of physical function or the mental component 
summary of SF-36. However, there was a statistically significant difference in favor of the intervention group in the physical component summary of SF-36 (mean difference 5.9 points, $95 \%$ CI 2.0 to $9.7, \mathrm{p}=0.003)$.

\section{DISCUSSION}

There was no between group difference evident in physical function (SPPB) at eight months follow-up. However, statistically significant differences in favor of the intervention group were found in six-minute walk test and the physical component summary of SF-36. These results suggest some positive lasting effects on fitness and physical HRQOL compared to immediate effects after a group-based multicomponent high intensity exercise program (Sunde et al., 2020).

The SPPB has been shown to be a robust measure of physical performance in community-dwelling older people (Westman et al., 2019). However, one possible explanation for the lack of a statistically significant difference between the groups in SPPB, while still finding a difference in the six-minute walk test, could be that the SPPB is less sensitive to change than the six-minute walk test in this study population. A second reason could be a ceiling effect in SPPB. A third reason could be the rather low sample size, as the mean between group difference of 0.5 points in SPPB could be considered a small meaningful change in community-dwelling older adults (Perera et al., 2006).

The mean between group difference in distance walked over 6 minutes at eight-month follow-up was 32.9 meters. This difference is statistically significant and clinically meaningful, as a change of 20 meters has been defined as a small meaningful change in older adults (Perera et al., 2006). Further, the mean between group difference in the physical component summary of SF-36 at eight months follow-up of 5.9 points can also be considered 
2 clinically meaningful. Our results regarding HRQOL are in line with a meta-analysis studying

3 the effects of exercise interventions on quality of life in clinical and healthy populations

4 (Gillison et al., 2009). The meta-analysis suggested small but meaningful improvement in

5 HRQOL, with greater improvements in physical quality of life associated with moderate

6 intensity interventions compared to light intensity. Interestingly, the results for psychological

7 quality of life showed larger improvements for interventions with light rather than moderate

8 intensity (Gillison et al., 2009).

The results show that the between group differences that were statistically significant after the intervention end remained significant at eight-month follow-up, despite the withdrawal of the intervention. This is a very interesting finding. Normally, the physiological response that are associated with an exercise intervention disappear or are markedly reduced a few months after cessation of training (American College of Sports et al., 2009). The results suggest that many of the participants in the intervention group succeeded in carrying on with home-based training after the intervention stopped. However, we have no information on this issue due to the feedback from the first 20 participants. We believe that the inclusion and encouragement of the home exercises in the multicomponent exercise program were essential to this success. During the intervention sessions the physical therapists repeatedly told the participants that the home exercises were very important and encouraged the participants to perform the exercises at least once a week. When the participants needed to skip one or several sessions, the physical therapists encouraged the participants to perform the home exercises at least three times each week. This practice could have made the participants used to doing the exercises on their own and better prepared to continue exercising after the cessation of the intervention. 


\section{Strengths and limitations}

3 This research contributes new knowledge on the longer-term effects of a group-based high

4 intensity multicomponent exercise program on physical function and HRQOL in older adults with or at risk of mobility disability after discharge from hospital, a segment of the population of older adults that is often excluded for intervention trials.

Some limitations should be mentioned. We did not reach the estimated sample size. Hence, we cannot conclude definitively regarding the effect of the intervention. Further, the attrition rate was rather high, with 31 of 89 participants lost to follow-up at eight months (34.8\%). However, mixed models are considered a robust method for dealing with missing data in studies investigating effects of an intervention (Xi et al., 2018). Furthermore, information on the exercise habits of the participants in the follow-up period between intervention end and 4 months follow-up would have added valuable information to the study. Finally, the follow-up time of the present study was quite short, hence the effects of the intervention beyond four months post-intervention cannot be evaluated.

\section{CONCLUSION: A group-based multicomponent exercise program can improve functional} capacity and physical HRQOL in a group of older adults with or at risk of mobility disability after discharge from hospital four months post-intervention. Interventions aiming to maintain or increase physical function and HRQOL should be encouraged in this population.

\section{ACKNOWLEDGMENTS}


2 We are sincerely grateful to the participants for their contribution to the study, and to the

physical therapists involved in testing the participants. In addition, we would like to thank all

the employees at the hospital who contributed to the study in one way or another.

\section{REFERENCES}

American College of Sports, M., Chodzko-Zajko, W. J., Proctor, D. N., Fiatarone Singh, M. A., Munson, C. T., Nigg, C. R., Salem, G. J., \& Skinner, J. S. (2009). American College of Sports Medicine position stand. Exercise and physical activity for older adults. Medicine and Science in Sports and Exercise, 41(7), 1510-1530. https://doi.org/10.1249/MSS.0b013e3181a0c95c

Bohannon, R. W. (2017). Test-Retest Reliability of Measurements of Hand-Grip Strength Obtained by Dynamometry from Older Adults: A Systematic Review of Research in the PubMed Database. J Frailty Aging, 6(2), 83-87. https://doi.org/10.14283/jfa.2017.8

Brovold, T., Skelton, D. A., \& Bergland, A. (2013). Older adults recently discharged from the hospital: effect of aerobic interval exercise on health-related quality of life, physical fitness, and physical activity. Journal of the American Geriatrics Society, 61(9), 1580-1585. https://doi.org/10.1111/igs.12400

Brown, C. J., Redden, D. T., Flood, K. L., \& Allman, R. M. (2009). The underrecognized epidemic of low mobility during hospitalization of older adults. Journal of the American Geriatrics Society, 57(9), 1660-1665. https://doi.org/10.1111/j.1532-5415.2009.02393.x

Brown, C. J. M. D. M., Kennedy, R. E. M. D. P., Lo, A. X. M. D. P., Williams, C. P. M. P. H., \& Sawyer, P. P. (2016). Impact of Emergency Department Visits and Hospitalization on Mobility Among Community-Dwelling Older Adults. American Journal of Medicine, 129(10), 1124.e11291124.e1115. https://doi.org/https://doi.org/10.1016/j.amjmed.2016.05.016

Brown, J. D., Lo-Ciganic, W.-H., Shao, H., Pahor, M., \& Manini, T. M. (2020). Trajectories of Short Physical Performance Battery Are Strongly Associated with Future Major Mobility Disability: Results from the LIFE Study. Journal of Clinical Medicine, 9(8), 2332.

Bruun, I. H., Maribo, T., Norgaard, B., Schiottz-Christensen, B., Jessen, M. G. B., \& Mogensen, C. B. (2018). The effect of systematic functional assessment and immediate rehabilitation on physical performance in acutely admitted older adults with reduced functional performance: a randomised clinical trial. Disability and Rehabilitation, 42(1), 1-10. https://doi.org/10.1080/09638288.2018.1492034

Buurman, B. M., Hoogerduijn, J. G., de Haan, R. J., Abu-Hanna, A., Lagaay, A. M., Verhaar, H. J., Schuurmans, M. J., Levi, M., de Rooij, S. E., \& Lama, J. R. (2011). Geriatric Conditions in Acutely Hospitalized Older Patients: Prevalence and One-Year Survival and Functional Decline (Geriatric Conditions: Prevalence and Outcomes). PloS One, 6(11), e26951. https://doi.org/https://doi.org/10.1371/journal.pone.0026951

Crapo, R. O., Casaburi, R., Coates, A. L., Enright, P. L., MacIntyre, N. R., McKay, R. T., Johnson, D., Wanger, J. S., Zeballos, R. J., Bittner, V., \& Mottram, C. (2002). ATS statement: Guidelines for the six-minute walk test. American Journal of Respiratory and Critical Care Medicine, 166(1), 111-117. https://doi.org/https://doi.org/10.1164/ajrccm.166.1.at1102

Esain, I., Gil, S. M., Bidaurrazaga-Letona, I., \& Rodriguez-Larrad, A. (2019). Effects of 3 months of detraining on functional fitness and quality of life in older adults who regularly exercise. Aging Clinical and Experimental Research, 31(4), 503-510. https://doi.org/10.1007/s40520$\underline{018-0990-1}$ 
Fletcher, G. F., Ades, P. A., Kligfield, P., Arena, R., Balady, G. J., Bittner, V. A., Coke, L. A., Fleg, J. L., Forman, D. E., \& Gerber, T. C. (2013). Exercise standards for testing and training: a scientific statement from the American Heart Association. Circulation, 128(8), 873-934. https://doi.org/https://doi.org/10.1161/CIR.0b013e31829b5b44

Folstein, M. F., Folstein, S. E., \& McHugh, P. R. (1975). "Mini-mental state". A practical method for grading the cognitive state of patients for the clinician. Journal of Psychiatric Research, 12(3), 189-198. https://doi.org/10.1016/0022-3956(75)90026-6

Fried, L. P., Bandeen-Roche, K., Kasper, J. D., \& Guralnik, J. M. (1999). Association of comorbidity with disability in older women: the Women's Health and Aging Study. Journal of Clinical Epidemiology, 52(1), 27-37.

Garber, C. E., Blissmer, B., Deschenes, M. R., Franklin, B. A., Lamonte, M. J., Lee, I. M., Nieman, D. C., Swain, D. P., \& American College of Sports, M. (2011). American College of Sports Medicine position stand. Quantity and quality of exercise for developing and maintaining cardiorespiratory, musculoskeletal, and neuromotor fitness in apparently healthy adults: guidance for prescribing exercise. Medicine and Science in Sports and Exercise, 43(7), 13341359. https://doi.org/https://doi.org/10.1249/MSS.0b013e318213fefb

Garber, C. E., Greaney, M. L., Riebe, D., Nigg, C. R., Burbank, P. A., \& Clark, P. G. (2010). Physical and mental health-related correlates of physical function in community dwelling older adults: a cross sectional study. BMC Geriatrics, 10(1), 1-10.

Gill, T. M., Allore, H. G., Holford, T. R., \& Guo, Z. (2004). Hospitalization, restricted activity, and the development of disability among older persons. JAMA, 292(17), 2115-2124. https://doi.org/10.1001/jama.292.17.2115

Gillison, F. B., Skevington, S. M., Sato, A., Standage, M., \& Evangelidou, S. (2009). The effects of exercise interventions on quality of life in clinical and healthy populations; a meta-analysis. Social Science and Medicine, 68(9), 1700-1710. https://doi.org/10.1016/j.socscimed.2009.02.028

Guralnik, J. M., Ferrucci, L., Pieper, C. F., Leveille, S. G., Markides, K. S., Ostir, G. V., Studenski, S., Berkman, L. F., \& Wallace, R. B. (2000). Lower extremity function and subsequent disability: consistency across studies, predictive models, and value of gait speed alone compared with the short physical performance battery. Journals of Gerontology. Series A: Biological Sciences and Medical Sciences, 55(4), M221-M231.

Guralnik, J. M., Simonsick, E. M., Ferrucci, L., Glynn, R. J., Berkman, L. F., Blazer, D. G., Scherr, P. A., \& Wallace, R. B. (1994). A short physical performance battery assessing lower extremity function: association with self-reported disability and prediction of mortality and nursing home admission. Journal of Gerontology, 49(2), M85-94. https://doi.org/https://doi.org/10.1093/geronj/49.2.m85

Halsaa, K. E., Brovold, T., Graver, V., Sandvik, L., \& Bergland, A. (2007). Assessments of interrater reliability and internal consistency of the Norwegian version of the Berg Balance Scale. Archives of Physical Medicine and Rehabilitation, 88(1), 94-98. https://doi.org/10.1016/j.apmr.2006.10.016

Health, U. S. D. o., Human Services, F. D. A. C. f. D. E., Research, Health, U. S. D. o., Human Services, F. D. A. C. f. B. E., Research, Health, U. S. D. o., Human Services, F. D. A. C. f. D., \& Radiological, H. (2006). Guidance for industry: patient-reported outcome measures: use in medical product development to support labeling claims: draft guidance. Health Qual Life Outcomes, 4, 79. https://doi.org/https://doi.org/10.1186/1477-7525-4-79

Helvik, A. S., Engedal, K., \& Selbaek, G. (2013). Change in quality of life of medically hospitalized patients--a one-year follow-up study. Aging \& Mental Health, 17(1), 66-76. https://doi.org/https://doi.org/10.1080/13607863.2012.715137

Jadczak, A. D., Makwana, N., Luscombe-Marsh, N., Visvanathan, R., \& Schultz, T. J. (2018). Effectiveness of exercise interventions on physical function in community-dwelling frail older people: an umbrella review of systematic reviews. JBI Database System Rev Implement Rep, 16(3), 752-775. https://doi.org/10.11124/JBISRIR-2017-003551 
Loyd, C., Beasley, T. M., Miltner, R. S., Clark, D., King, B., \& Brown, C. J. (2018). Trajectories of Community Mobility Recovery After Hospitalization in Older Adults. Journal of the American Geriatrics Society, 66(7), 1399-1403. https://doi.org/10.1111/igs.15397

Machón, M., Larrañaga, I., Dorronsoro, M., Vrotsou, K., \& Vergara, I. (2017). Health-related quality of life and associated factors in functionally independent older people. BMC Geriatrics, 17(1), 19. https://doi.org/https://doi.org/10.1186/s12877-016-0410-3

McKelvie, S., Hall, A. M., Richmond, H. R., Finnegan, S., \& Lasserson, D. (2018). Improving the rehabilitation of older people after emergency hospital admission. Maturitas, 111, 20-30. https://doi.org/https://doi.org/10.1016/j.maturitas.2018.02.011

NDH. (2016, 04/2016). Øvelser for å forebygge fall - For deg som føler deg litt ustø når du går utendørs. Retrieved 26.06.20 from https://www.helsenorge.no/globalassets/dokumenter/ntnu fallforebygging 1 2016-ny.pdf

Pavasini, R., Ferrer Forés, M., \& Campo, G. (2016). Short Physical Performance Battery and all-cause mortality: systematic review and meta-analysis. BMC Medicine, 14(1). https://doi.org/10.1186/s12916-016-0763-7

Perera, S., Mody, S. H., Woodman, R. C., \& Studenski, S. A. (2006). Meaningful change and responsiveness in common physical performance measures in older adults. Journal of the American Geriatrics Society, 54(5), 743-749. https://doi.org/10.1111/j.1532$\underline{5415.2006 .00701 . x}$

Schulz, K. F., Altman, D. G., Moher, D., \& Group, C. (2010). CONSORT 2010 statement: updated guidelines for reporting parallel group randomised trials. PLoS Med, 7(3), e1000251. https://doi.org/10.1371/journal.pmed.1000251

Sunde, S., Hesseberg, K., Skelton, D. A., Ranhoff, A. H., Pripp, A. H., Aarønæs, M., \& Brovold, T. (2020). Effects of a multicomponent high intensity exercise program on physical function and health-related quality of life in older adults with or at risk of mobility disability after discharge from hospital: a randomised controlled trial. BMC Geriatrics, 20(1), 464. https://doi.org/https://doi.org/10.1186/s12877-020-01829-9

Tomas-Carus, P., Hakkinen, A., Gusi, N., Leal, A., Hakkinen, K., \& Ortega-Alonso, A. (2007). Aquatic training and detraining on fitness and quality of life in fibromyalgia. Medicine and Science in Sports and Exercise, 39(7), 1044-1050. https://doi.org/10.1249/01.mss.0b0138059aec4

Verweij, L., van de Korput, E., Daams, J. G., Ter Riet, G., Peters, R. J. G., Engelbert, R. H. H., Scholte Op Reimer, W. J. M., \& Buurman, B. M. (2019). Effects of Postacute Multidisciplinary Rehabilitation Including Exercise in Out-of-Hospital Settings in the Aged: Systematic Review and Meta-analysis. Archives of Physical Medicine and Rehabilitation, 100(3), 530-550. https://doi.org/https://doi.org/10.1016/j.apmr.2018.05.010

Ware, J. E., Jr., \& Sherbourne, C. D. (1992). The MOS 36-item short-form health survey (SF-36). I. Conceptual framework and item selection. Medical Care, 30(6), 473-483. https://www.ncbi.nlm.nih.gov/pubmed/1593914

Westman, A. W., Combs-Miller, S., Moore, J., \& Ehrlich-Jones, L. (2019). Measurement Characteristics and Clinical Utility of the Short Physical Performance Battery Among Community-Dwelling Older Adults. Archives of Physical Medicine and Rehabilitation, 100(1), 185-187. https://doi.org/10.1016/i.apmr.2018.06.003

WHO. (2010). Global recommendations on physical activity for health. Geneva World Heal Organ, 60. WHO. (2015). World report on ageing and health. World Health Organization.

WHO. (2017). Global strategy and action plan on ageing and health.

Xi, W., Pennell, M. L., Andridge, R. R., \& Paskett, E. D. (2018). Comparison of intent-to-treat analysis strategies for pre-post studies with loss to follow-up. Contemporary Clinical Trials, 11, 20-29. https://doi.org/https://doi.org/10.1016/j.conctc.2018.05.008 


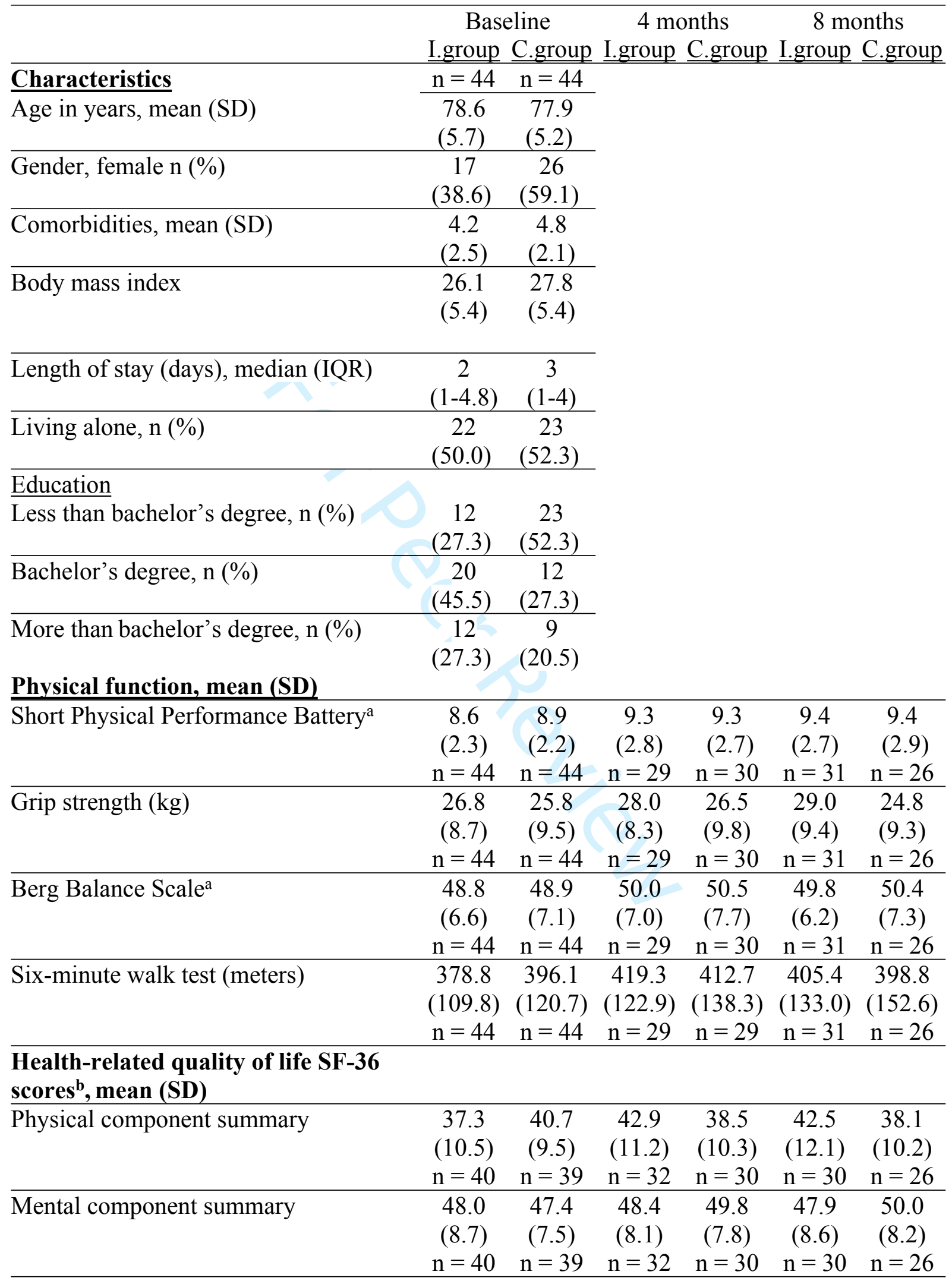

3 I.group $=$ Intervention Group, C.group $=$ Control group, $\mathrm{N}=$ number of individuals, $\mathrm{SD}=$

4 Standard Deviation, SF-36 = the medical Outcome 36 -Item Short Form Survey, IQR = Inter

5 Quartile Range. 


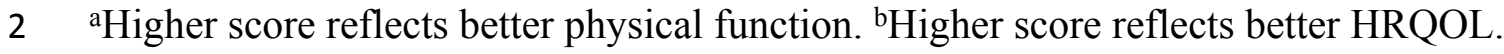

3

4 Table 2. Differences between groups at 8 months follow-up, adjusted for baseline values.

5 Mean difference refers to intervention minus control

\begin{tabular}{llll}
\hline Outcome measures & Mean Difference & $95 \%$ CI & P-value
\end{tabular}

\section{Physical function}

Short Physical Performance Battery ${ }^{\mathrm{a}}$

0.5

-0.6 to $1.5 \quad 0.378$

Berg Balance Scale ${ }^{a}$

$-0.2$

-1.8 to $1.4 \quad 0.827$

Grip strength $(\mathrm{kg})$

-0.3 to $3.2 \quad 0.092$

Six-minute walk test (meters)

$$
1.5 \text { to } 64.3 \mathbf{0 . 0 4 0}
$$

$\underline{\text { Health-related quality of life }}$
Physical Component Summary of SF-36 ${ }^{\mathrm{b}}$
2.0 to $9.7 \quad \mathbf{0 . 0 0 3}$
Mental Component Summary of SF-36
$-0.8$
-3.9 to $2.2 \quad 0.588$

Body Mass Index calculated using the formula weight $/ \mathrm{m}^{2}$. SF-36 $=$ the medical Outcome $36-$ Item Short form Survey. Statistically significant $\mathrm{p}$-values are in bold. The level of

8 significance was set at 0.05 .

$9 \quad{ }^{a}$ Higher score reflects better physical function. ${ }^{b}$ Higher score reflects better HRQOL. 


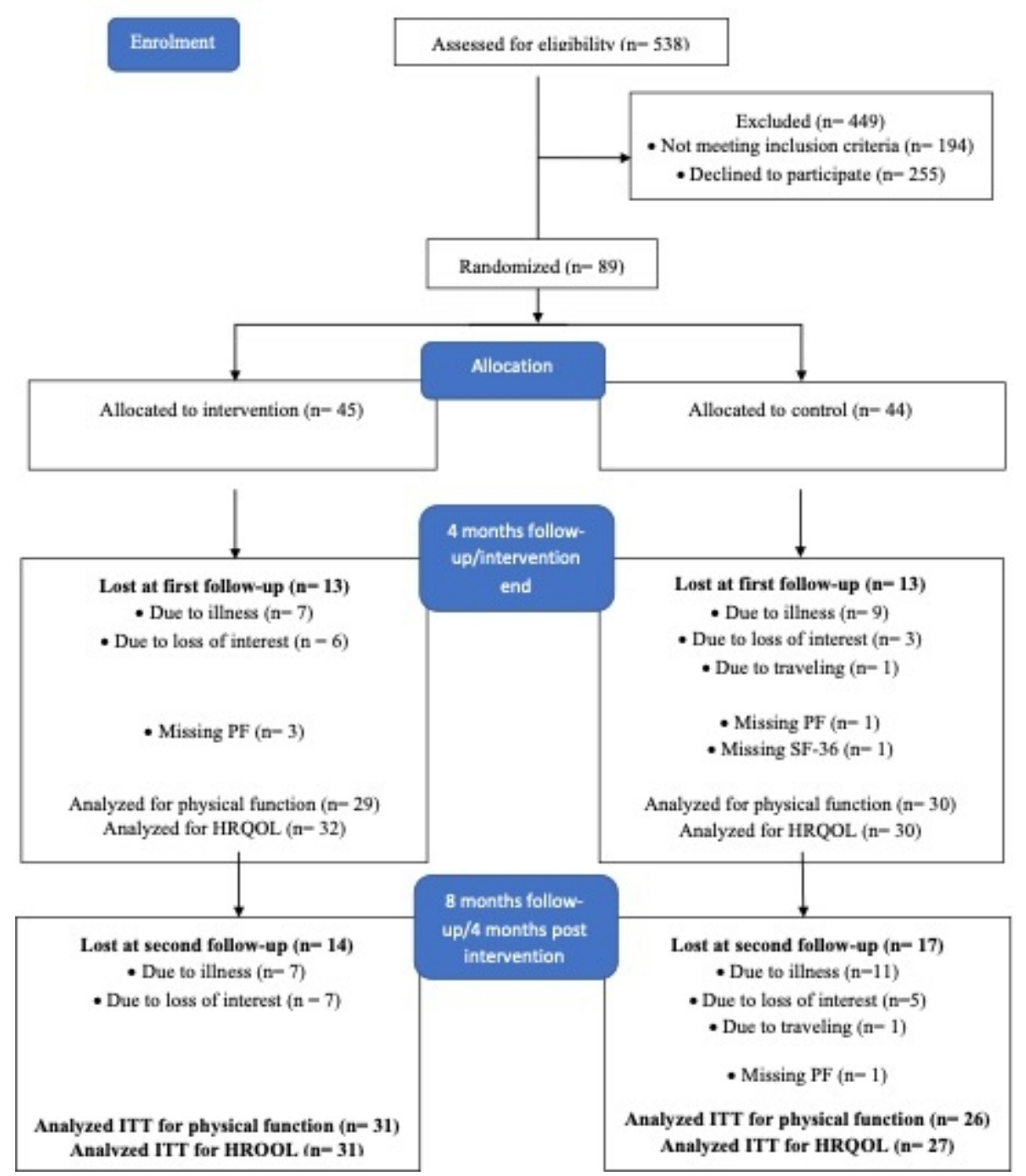

Figure 1. Flow of the participants throughout the study period (CONSORT 2010 Flow Diagram) $159 \times 206 \mathrm{~mm}(72 \times 72 \mathrm{DPI})$ 